\title{
Japón y México: el inicio de sus relaciones y la inmigración japonesa durante el Porfiriato
}

DOI: $10.32870 /$ mycp.v1i1.387

Héctor Palacios

\section{Resumen}

A mediados del siglo XIX los sucesos políticos y militares ocurridos en Japón y México comenzaron a transitar por senderos parecidos ante las presiones externas y las inestabilidades internas de cada cual. Al final de esos caminos paralelos aparecía la meta de ser Estados-nación modernos capaces de unirse al "orden" internacional. Así, en algún momento ambas naciones tuvieron que encontrarse: en 1888 acordaron un Tratado de Amistad, Navegación y Comercio, el primero en su tipo firmado por Japón en condiciones de igualdad. Una de las consecuencias de ese acuerdo — quizá la más significativa - fue el flujo migratorio de Japón a México inaugurado en 1897 por aquellos migrantes enviados por el vizconde Enomoto al estado de Chiapas. A la vuelta de siglo, los japoneses comenzarían a desembarcar por miles en puertos mexicanos. Unos cuantos de esos oriundos del país del sol naciente pasarían por Guadalajara, caso específico que se aborda en la parte final de este artículo.

Palabras clave: historia, Japón, México, migración, relaciones bilaterales, Meiji, Porfiriato, Guadalajara.

Artículo recibido el 03 de mayo de 2012 y dictaminado el 23 de mayo de 2012.

Héctor Palacios: Investigador independiente y licenciado con especialización en Historia por la Universidad de Guadalajara. El autor agradece el apoyo recibido de Susumo Azano Moritani para la investigación sobre migración japonesa a Guadalajara a finales del siglo XIX y principios del XX, de la cual este artículo constitiye un avance de investigación. 


\section{Abstract}

At mid-19th Century, political and military facts from Japan and Mexico began to walk by similar paths because external pressures and internal instability of each one. At the end of that ways was the promise of became modern nationstates able to join to international "order". Then, in some moment both nations met themselves: they signed in 1888 a Friendship, Navigation and Commerce Agreement, the first one of its type gotten by Japan about equality conditions. One of the consequences of this Agreement - maybe the most importantwas the migratory flux from Japan to Mexico, started at 1897 by the migrants sent by viscount Enomoto to Mexican state of Chiapas. Beginning the 20th Century, thousands of Japanese arrived to Mexican ports. A few of them stayed in Guadalajara city, specific case broached on final pages of this article.

Keywords: History, Japan, Mexico, migration, bilateral relationships, Meiji, Porfiriato, Guadalajara.

Este artículo inicia con una síntesis de las historias políticas generales de Japón y México, desde finales de la década de 1840 hasta finales de la de 1870, donde llaman la atención aquellos aspectos de similitud que corren paralelos en ambos lados. Lo anterior conduce de algún modo a un punto de encuentro entre estos dos países lejanos uno del otro; así, en 1888 se firma el primer tratado oficial entre México y Japón. Una de las consecuencias más importantes de ese acuerdo fue el flujo migratorio que comenzó a correr desde el archipiélago japonés hacia tierras mexicanas. En 1897 llegaría el primer grupo de japoneses a las costas de Chiapas, y de 1901 a 1907 arribarían varios miles más a distintas zonas del país, aunque la mayoría venían con la idea de transmigrar a Estados Unidos. En este texto se comentan en general las posibles causas de la emigración japonesa de finales del siglo XIX y principios del Xx, y se aborda brevemente el cierre de ese flujo migratorio hacia México en 1907. Finalmente, como una especie de anexo, se comparte el caso específico de los japoneses que llegaron a la ciudad Guadalajara entre 1900 y 1911 ; esa parte es apenas un adelanto de los primeros hallazgos que se tienen al respecto.

\section{Japón y México. Las historias previas y su paralelismo}

Buscar las causas que originaron la llegada a México de migrantes japoneses en la época del Porfiriato, implica sumergirse en la historia política de Japón 
y de México de aquellos años, cuando comenzaron a andar el camino que los llevaría a constituirse en Estados-nación modernos. En ese ejercicio indagatorio es inevitable llegar a la conclusión de que ambos países vivieron procesos históricos paralelos y con ciertas similitudes.

Japón. En el siglo XVII Japón cerró sus puertas: nadie entraría ni saldría del archipiélago sin permiso del gobierno del shogunato Tokugawa. Así pasaron más de dos siglos. El aislamiento nipón comenzó a ver su fin con la llegada de negras naves de guerra estadounidenses a la Bahía de Edo, las cuales navegaban bajo el mando del comodoro Matthew $C$. Perry, mismo que pocos años atrás había participado de manera destacada en los bombardeos al puerto de Veracruz, México.

Desde principios del siglo XIX existía la presión externa hacia Japón para que abriera sus fronteras al comercio internacional; primero fueron los rusos, después los británicos, luego una primera petición de Estados Unidos en $1837 .{ }^{1}$ Holanda era la única nación europea con la que Japón había mantenido contacto comercial durante casi 250 años. El shogun recibió en 1844 una carta del rey holandés Guillermo II, en la cual advertía al gobierno nipón que los tiempos en el mundo habían cambiado, que era momento de dejar la política de aislamiento, o las consecuencias para los japoneses podían ser graves. ${ }^{2}$

Pero el gobierno shogunal hizo oídos sordos. Tuvieron que ser los amenazantes barcos de guerra de Estados Unidos los que dieran a entender las palabras escritas por aquel monarca europeo. El enviado oficial de la nación americana, Matthew $C$. Perry, entregó al shogun la petición de abrir las costas japonesas a los barcos estadounidenses; un año después, 1854, el comodoro regresó con nueve barcos de guerra por una respuesta. El Bakufu (o gobierno shogunal) no tuvo otra opción más que ceder ante las presiones de una fuerza militar a la que no podía hacer frente.

De inmediato, otras potencias marítimas aprovecharon la brecha abierta por los norteamericanos. Así, Rusia y Gran Bretaña también obtuvieron acceso a las costas niponas. Para 1858 se firmarían tratados desiguales: entre julio y octubre de ese año Japón selló una relación inequitativa con los Estados Unidos, Holanda, Rusia, Gran Bretaña y Francia. Sin embargo, el orgullo japonés había sido provocado.

1. Gordon, 2009: 47-51.

2. Beasley, 1989: 263. 
La firma de dichos tratados desiguales y la presencia extranjera produjeron ánimos adversos hacia el régimen del shogun Tokugawa, empezando por la Corte imperial, sometida al mero protocolo desde siglos atrás; el emperador protestó al sentir que se había violado la voluntad de los ancestros, la cual era mantener a Japón aislado del resto del mundo. La misión histórica del shogun era defender las fronteras niponas de los "bárbaros" o de amenazas externas; por tanto, se creía que el shogun había fallado en su misión original. La legitimidad de su poder estaba en entredicho.

Por otra parte, samuráis de medio y bajo rango, pero bien preparados y con méritos acumulados en la administración de las tierras de sus respectivos daimio, ${ }^{3}$ vislumbraron la coyuntura para trastocar un sistema bajo el cual difícilmente podían ascender de estatus político, económico y social. Muchos de esos samuráis, en su mayoría jóvenes, esparcieron la idea de reinstaurar al emperador como la figura gobernante de facto y desplazar al shogun y a su gobierno, que habían fallado en sus funciones.

Cabe explicar que el Bakufu, en un principio, cedió ante las presiones extranjeras al entender que la tecnología militar de aquéllos era infinitamente superior a la japonesa, la cual se había estancado durante los años de paz y aislamiento. El gobierno shogunal comprendió que usar la fuerza para hacer valer su derecho de autodeterminación sería fatal para el pueblo japonés, ya que desde el inicio sería una lucha perdida.

Por otra parte, cuando el comercio exterior empezó a rondar al amparo de los tratados firmados, muchos funcionarios del gobierno de Edo empezaron a ver los beneficios económicos que esta actividad traía a sus arcas personales, aspecto que seguro exacerbó aún más a la naciente oposición antishogunal. También, ante esa creciente oposición, el Bakufu empezó a comprar armamento moderno a los extranjeros para hacer frente a sus detractores. Era un hecho que los tiempos de paz habían terminado en Japón.

Es necesario mencionar que el emperador no había ratificado los tratados firmados por el gobierno del shogun, aspecto fundamental en el protocolo nipón. La ruptura estructural ya no tenía remedio. Entre 1862 y 1863 Kyoto se llenó de samuráis que se declaraban leales al emperador en su confrontación contra el shogun y a la exigencia de expulsar a los extranjeros. En ese año de 1863, guerreros del señorío de Chōshū, ubicado al sureste de Honshu (la isla principal de Japón), atacaron por su cuenta a una embarcación estadouni-

3. La palabra daimio se puede entender en términos generales como señor(es) feudal(es). 
dense; ese mismo año hubo intercambio de fuego en Kagoshima entre naves británicas y las defensas del señorío de Satsuma, ubicado al sur de la isla de Kyūshū. La reacción antiextranjera en Japón estaba en su máximo punto.

En 1864 se emprendió un ataque conjunto desde mar por parte de fuerzas de Gran Bretaña, Francia, Holanda y Estados Unidos contra Chōshū con el fin de reabrir el paso del Estrecho de Shimonoseki, y así permitir el tránsito seguro y libre de las embarcaciones mercantes. Al año siguiente terminó la Guerra Civil de Estados Unidos; entonces muchas de las armas utilizadas en ese conflicto fueron revendidas a precios bajos en Japón, tanto al gobierno del shogun como a sus opositores. ${ }^{4}$

El año 1866 fue clave para toda esta cadena (o mezcla) de hechos que marcaban un cambio de época en Japón. En ese año murió el shogun Tokugawa Iemochi y ascendió Tokugawa Yoshinobu. Ese mismo año el Bakufu trató de someter mediante las armas a los rebeldes de Chōshū y Satsuma, pero fracasó. Más allá de lo militar, Yoshinobu intentó establecer reformas para hacer de Japón un Estado moderno, pero la suerte del régimen Tokugawa ya estaba definida.

Para colmo, el aumento de precios, ocasionado por la especulación de metales propiciada por los comerciantes extranjeros, llegó a su punto más alto en ese fatídico año. Hubo disturbios en los centros urbanos de mayor población y vinieron aún más noticias: a principios de 1867 murió el emperador Komei, quien se oponía a la presencia extranjera en Japón pero sin cuestionar el poder del shogun; por el contrario, exigía que el Bakufu cumpliera con su deber de expulsar a los "bárbaros".

Ascendió entonces el emperador Meiji, quien apenas era un adolescente. Tokugawa Yoshinobu decidió renunciar al título del shogun y regresar dicho nombramiento al emperador. No obstante, Yoshinobu continuaría teniendo un gran poder político debido a la enorme extensión territorial del señorío de los Tokugawa. Yoshinobu se mudó de Edo (la sede del shogun) a Kyoto (la sede del emperador), donde él y su gente siguieron ejerciendo el poder a la sombra del joven emperador. No pasaría mucho tiempo para que los detractores del viejo régimen reaccionaran.

En enero de 1868 las fuerzas de Chōshū y Satsuma dieron un golpe de Estado con el que abolieron definitivamente al Bakufu, e imponían la restauración total del emperador como cabeza única del Estado japonés. Las potencias

4. Kaibara, 2000: 227. 
extranjeras desde luego no estuvieron al margen de esto; irónicamente, todas, excepto Francia, apoyaron la restauración del emperador: se habían dado cuenta de que el debilitamiento del Bakufu ya no tenía solución. Las fuerzas Tokugawa, con apoyo de los franceses, opusieron cierta resistencia, pero su causa estaba perdida. El cambio de los tiempos en Japón seguía en marcha. En ese mismo año de 1868, el emperador, su corte y el nuevo gobierno en general se mudaron a Edo y la renombraron como Tokio (capital del Este).

Las primeras reformas hechas por el gobierno imperial fueron contundentes para la formación y consolidación del Estado moderno japonés. Se intentará mencionar algunas de ellas a continuación. Para empezar, los centenarios señoríos feudales fueron abolidos y convertidos en prefecturas. Algunos de los daimios o señores feudales pasaron a ser gobernadores de dichas prefecturas, otros fueron atraídos a Tokio para formar parte del nuevo gobierno, y otros simplemente fueron pensionados con la condición de ceder su poder regional. Para los observadores de la época como para los historiadores actuales, sorprende que en sólo tres años haya desaparecido la vieja división feudal japonesa.

Se promulgaron ciertas libertades y derechos para el pueblo en general, como el de poder tener un apellido, aspecto antes reservado para los estratos sociales altos; también se concedió la libertad de oficio, se estableció el principio de la libertad religiosa, pero con el sintoísmo como religión nacional. También se promulgó la obligatoriedad del registro de nombres, de domicilios, de nacimientos, defunciones, etcétera.

Empezaron a tejerse la red de telégrafos, un servicio postal moderno y líneas de ferrocarril. En 1872 se inauguró el primer tramo de vías férreas, que iba de Yokohama a Tokio. En ese mismo año se promulgó la obligatoriedad de la enseñanza primaria para los niños japoneses (un año antes se había establecido el Ministerio de Educación). Por otra parte, en 1872 se creó el Ministerio del Ejército.

Un aspecto importante para el funcionamiento del nuevo Estado japonés fue la centralización de la recolección de impuestos, de la cual se encargó directamente el Gobierno imperial. El sistema tributario japonés se fue articulando paulatinamente en conjunto con la introducción del sistema capitalista en Japón.

Para los japoneses fue frustrante haber cedido ante la diplomacia de los cañoneros de las potencias extranjeras. El nuevo gobierno pronto entendió que necesitaban empezar a crear una fuerza militar que en algún momento se 
pudiera igualar a la de aquellos con los que había firmado tratados desiguales, y entrar así al mismo juego "diplomático" para poder revertir dichos tratados.

Un primer paso fue dado en 1871, al crearse el Ejército imperial con 10 mil hombres reclutados de las fuerzas que participaron en la Restauración. Dos años más tarde, en 1873 , se decretó el servicio militar obligatorio para los hombres mayores de 20 años de edad. Esta medida fue sumamente antipopular, ya que afectaba principalmente a miles y miles de jóvenes pertenecientes a familias campesinas. Incluso hubo decenas de manifestaciones violentas en contra de dicho decreto. ${ }^{5}$

El siguiente paso sería uno de los más complicados que tuvo que dar el Gobierno imperial: abolir la clase samurai, la misma que durante cientos de años había gobernado Japón. El problema principal era que las pensiones a las que tenía acceso esta clase, compuesta por más de un millón y medio de individuos, representaban $30 \%$ del presupuesto gubernamental. ${ }^{6} \mathrm{Al}$ abolir el estatus de "samurai" se les brindó a los tradicionales guerreros la opción de incorporarse al Ejército imperial; muchos optaron por aceptar unos bonos de inversión pagable a mediano plazo; otros se convirtieron en campesinos, comerciantes o aprendieron algún oficio.

Lo paradójico en este caso, es que ellos fueron los actores fundamentales de la caída del shogunato y de la restauración del emperador. No obstante, aquellos que accedieron a la dirigencia gubernamental se dieron cuenta de que la clase samurai no cabía más en la construcción del nuevo Estado. No todos lo aceptaron así. En 1877 el Ejército imperial tendría su primer gran reto contra la última resistencia de la antigua clase guerrera, dirigida por el respetado líder Saigō Takamori, de Satsuma, cuyo ejército fue completamente vencido. El Gobierno Meiji seguía avanzando en sus propósitos reformadores.

México. Dejemos un momento lo que sucedía en Japón y regresemos en el espacio y el tiempo: Puerto de Veracruz, México, año de 1847: Matthew C. Perry se lucía en el ataque naval contra dicho lugar; en ese entonces el Estadonación mexicano era sólo una ilusión; México tenía poco más de seis lustros de haberse constituido como una nación independiente. Durante tres siglos fue el virreinato de la Nueva España, una colonia de España. Las dificultades

5. Gordon, 2009: 66; Vlastos, 1989: 384.

6. Kaibara, 2000: 240. Cf. Gordon, 2009: 64 y 65. 
para levantar el nuevo Estado fueron enormes, empezando por la desunión y la constante rivalidad entre las distintas facciones políticas y regionales.

Entre las consecuencias se encuentra la pérdida de territorio al norte del país, iniciando con Texas, que se independizó en 1836 y que en 1845 se anexó a Estados Unidos. Justo un año después el Gobierno estadounidense declaró la guerra a México por "malos entendidos" fronterizos. El primer día de junio de 1846, fuerzas navales de aquel país tomaron Mazatlán, el puerto donde, poco tiempo atrás, habían salido de regreso a su tierra unos náufragos japoneses. ${ }^{7}$

Las fuerzas estadounidenses pronto tuvieron el control de los principales puertos del Pacífico-norte mexicano, de las principales poblaciones de California, incluida Los Ángeles, así como aquellas de Nuevo México, destacando Santa Fe. Otro frente de guerra se abrió por el noreste: los invasores tomaron la ciudad de Monterrey tras combatir una férrea resistencia civil de tres días. Se continuaría el avance hacia el sur sin que las milicias mexicanas pudieran hacer frente a la invasión de manera certera.

El cierre definitivo de estas acciones fue el desembarque militar en el puerto de Veracruz; desde ahí avanzaron las tropas estadounidenses hacia la ciudad de México, donde la resistencia fue más que nada simbólica y llena de mitos heroicos para los futuros libros de la historia oficial. La realidad es clara en obras pictóricas de la época: el Ejército de Estados Unidos entró triunfal a la capital mexicana y la bandera de las barras y las estrellas fue izada en el asta del Palacio Nacional el 15 de septiembre de 1847.

Estos hechos conllevaron a la pérdida territorial por parte de México de 2'400,000 kilómetros cuadrados. Con esto Estados Unidos había logrado expandirse de costa a costa, del Océano Atlántico al Océano Pacífico, y una nueva frontera se abría para los estadounidenses, una que miraba hacia el oeste y que estaba llena de mar. A los pocos años, en 1853, navíos estadounidenses llegaban con sus cañoneras cargadas a la Bahía de Edo, en Japón.

Después del desastre para México, siguió más desorganización política, más pugnas internas, más golpes de Estado. En 1853 se impuso una dicta-

7. En 1841 los tripulantes de una embarcación llamada Eiju Maru, de Osaka, fueron sorprendidos por una tormenta que los lanzó al naufragio; al estar a la deriva, unos contrabandistas españoles los secuestraron. Semanas después los náufragos japoneses fueron abandonados en la península de Baja California. De ahí empezó un nuevo peregrinar hasta llegar a Mazatlán, donde se fueron embarcando al puerto chino de Macao con el fin poder regresar a Japón. Véase: Yanaguida y Rodríguez del Alisal, 1992: 39-41. Sobre la invasión estadounidense en Mazatlán: Vázquez, 2000: 578. 
dura encabezada por un personaje emblemático — aunque no célebre- de la historia mexicana: Antonio López de Santa Anna. Pronto, al año siguiente, se levantaría un movimiento armado en su contra, conocido como la revolución de Ayutla, encabezada por el cacique del estado de Guerrero, Juan Álvarez. Para 1855 este movimiento triunfó y tomó las riendas del Gobierno central.

El viejo Álvarez se rodeó de jóvenes mentes liberales, que de inmediato se dieron a la tarea de diseñar leyes reformistas que consideraban urgentes para levantar a la nación de las cenizas de una vez por todas. En 1857 se proclamaría una nueva Constitución, la cual avivó más el fuego de las discordias: las viejas fuerzas reaccionarias instaban de nuevo al combate. De 1858 a 1860 los mexicanos se vieron envueltos en una guerra civil conocida como la Guerra de los Tres Años (o Guerra de Reforma), cuyo bando triunfador fue aquel que defendía el proyecto de nación proclamado en la Constitución de 1857. Pero la paz y la estabilidad estaban muy lejanas aún para este país.

La situación financiera del Gobierno mexicano, encabezado por Benito Juárez, era lamentable; se decidió entonces suspender el pago de deudas a naciones extranjeras. Ello incitó al apetito colonialista europeo a acercarse a México, aprovechando que su gran contrapeso en el hemisferio occidental, Estados Unidos, estaba inmerso en un fuerte conflicto interno: la Guerra de Secesión (también conocida como Guerra Civil).

Navíos de guerra de España, Inglaterra y Francia se estacionaron en el puerto de Veracruz: exigían el pago de la deuda que el gobierno de Juárez había suspendido. De inmediato se iniciaron negociaciones; un buen manejo diplomático logró que las flotas de Inglaterra y de España se retiraran, pero los franceses tenían otros planes. Una nueva guerra se avecinaba para los mexicanos.

Los efectivos militares franceses comenzaron a avanzar rumbo a la ciudad de México, pero toparon con pared en la ciudad de Puebla, lugar donde fueron derrotados por las fuerzas mexicanas un 5 de mayo de 1862, fecha celebrada aún hoy en día. Sin embargo, la Francia gobernada por Napoleón III tenía claro su plan expansionista en América, aprovechando, sin duda, que Estados Unidos estaba imposibilitado para intervenir en su contra.

Para principios de 1863 las tropas francesas, con un mayor número de combatientes, avanzaron en un nuevo intento por conquistar la capital de la República Mexicana. Otra vez la ciudad de Puebla sería un dolor de cabeza para los franceses, pero después de 62 largos días de resistencia del Ejército 
mexicano y de los habitantes de Puebla, ${ }^{8}$ lograron tomar la plaza y despejar el camino hacia la ciudad de México, la cual tuvo que abandonar el presidente Benito Juárez junto con sus ministros de Gobierno.

El plan de Napoleón III, respaldado e incluso gestionado por mexicanos de perfil elitista, conservador y promonárquico, era instalar una monarquía en México encabezada por un príncipe europeo que fuera afín a los intereses políticos y económicos de Francia. Fue así que en mayo de 1864 llegó a México el archiduque austriaco Maximiliano de Habsburgo con su esposa Carlota, hija del rey de Bélgica. Fueron coronados como emperador y emperatriz del Imperio mexicano. Aquello sonaba a cuento de hadas, pero estuvo muy lejos de serlo.

La resistencia republicana y nacionalista fue férrea contra los invasores. Juárez mantuvo el liderazgo a pesar de tener que emigrar de un lugar a otro hasta verse orillado en la frontera norte del país, en el estado de Chihuahua. Por todo el territorio había guerrillas antiimperialistas que no permitieron a los franceses y al gobierno de Maximiliano tener un control real del país.

Para peor fortuna del destino del proyecto de Napoleón III, en 1865 la Guerra Civil de Estados Unidos vio su fin. Ahora sí, el Gobierno de Washington podía concentrarse en lo que consideraba una amenaza a su seguridad territorial, al estar su vecino del sur invadido por un ejército europeo. Iniciaron en París las escaramuzas diplomáticas entre estadounidenses y franceses. Por otra parte, armas de última tecnología usadas en el conflicto estadounidense comenzaron a llegar a manos de la resistencia mexicana (tal como sucedió en Japón), la cual empezó a asestar duros golpes a los europeos.

La decisión se tomó entonces en París; las tropas francesas tendrían que abandonar el territorio mexicano; además, se aconsejó al emperador Maximiliano que abdicara y regresara a Europa; de otra manera, su gobierno quedaría bajo su propia suerte ya sin el apoyo militar francés. En marzo de 1867 las tropas francesas evacuaron territorio mexicano. En ese mismo año, muchos de esos soldados fueron enviados a otro país lejano, a otra misión fallida: fueron a dar a Japón para combatir a favor del gobierno del shogun, en contra de la restauración del emperador.

Maximiliano no quiso renunciar al trono; con el apoyo de un reducido ejército de mexicanos conservadores adeptos al Imperio, y de un reducido cuerpo de voluntarios belgas y austriacos que viajaron en su auxilio, decidió hacer frente a la resistencia republicana, que ante la evacuación de los franceses,

8. Zavala, 1990: 105. 
tenía ya bajo su control la mayor parte del país. Maximiliano y los principales jefes conservadores que pelearon por la causa monárquica fueron derrotados y capturados en mayo de ese año de 1867, en la ciudad de Querétaro. Días después el iluso príncipe europeo fue fusilado. El sistema republicano de corte liberal se reinstauraría en México, y por fin se intentaría llevar a cabo el proyecto de nación plasmado en la Constitución de 1857.

La primera etapa de esta reinstauración republicana fue encabezada por Benito Juárez de 1867 a 1872, año de su muerte, y por Sebastián Lerdo de Tejada, de 1872 a 1876. Durante estos años se intentó pacificar el país, aún no ausente de levantamientos regionales, de bandoleros y asaltantes de caminos. Se iniciaron las concesiones para construir líneas ferrocarrileras y redes de telégrafos; también se procedió a reconstruir las relaciones diplomáticas perdidas a lo largo de los años de conflictos bélicos.

Las discordias políticas seguían a flor de piel y la incapacidad de la élite política mexicana de instaurar un sistema democrático efectivo, perpetuaba los conflictos solucionados por las armas. Fue así que en 1876 el general Porfirio Díaz, mediante un movimiento armado desplazó de la presidencia a Sebastián Lerdo de Tejada, iniciando así una nueva etapa en la historia mexicana, conocida como el Porfiriato, que fue en sí, la continuación y consolidación del Estado nacional proyectado por los gobiernos de Juárez y Lerdo de Tejada.

El paralelismo cronológico cuenta para esta narración. En 1867 se echó abajo el intento de gobierno monárquico en México y se instauró un sistema republicano que buscaba crear un Estado-nación moderno. En 1868 se echó abajo el gobierno de tipo feudal en Japón, y se instauró, mediante la figura del emperador, un sistema de gobierno que buscaba crear un Estado-nación moderno. Una serie de reformas y acciones de reconstrucción nacional se iniciaron en ambos países. Esto mismo lo dice Juan José Ramírez Bonilla, pero con otras palabras:

El año de 1867 representa un punto de inflexión en la evolución de dos países tan disímbolos como son México y Japón: en el primero, el gobierno constitucional de don Benito Juárez derrotaba a los grupos que sostuvieron el imperio de Maximiliano de Habsburgo; en el segundo, el feudalismo japonés tocaba a su fin con la caída del shogunato de Tokugawa. En ambos países se inauguró entonces 
una nueva era marcada por la realización de denodados esfuerzos para preservar

la soberanía nacional y para modernizar las sociedades correspondientes. ${ }^{9}$

Añadiendo más datos a lo anterior, en 1876, en México, mediante las armas se instauró un gobierno fuerte encabezado por Porfirio Díaz, el cual consolidaría la creación de dicho Estado-nación moderno. En 1877, en Japón, se afianzó definitivamente el proyecto modernizador al derrotar militarmente a la oposición samurai encabezada por el respetable líder Saigō Takamori. Ambas naciones estaban cerca de encontrarse políticamente una con otra.

\section{El Tratado entre México y Japón}

Un hecho que sirvió como antecedente inmediato del primer lazo oficial amistoso entre México y Japón, fue el viaje de la Comisión Astronómica Mexicana de 1874: el primero en su tipo realizado por científicos mexicanos, cuya misión era observar el tránsito de Venus frente al disco solar (lo cual ocurre sólo dos veces cada siglo); el objetivo de esta actividad astronómica era calcular con exactitud la distancia entre el Sol y la Tierra. Los mexicanos lograron hacer dicha observación en Yokohama, Japón.

Francisco Díaz Covarrubias, quien encabezó la Comisión, y Francisco Bulnes, que viajó como cronista de la misma, al regresar a México expresaron su punto de vista sobre la conveniencia de entablar relaciones diplomáticas y comerciales con Japón, así como facilitar y promover la inmigración japonesa hacia territorio mexicano; sus comentarios hicieron algún eco en la opinión pública.

El primer acercamiento oficial al respecto ocurrió en 1882, en Washington, al entrevistarse Matías Romero, representante de México en Estados Unidos, con sus pares japoneses. A principios de 1883, el ministro de Relaciones Exteriores, Ignacio Mariscal, recibió una carta de Matías Romero donde le informaba sobre dicho acercamiento, mencionándole los esfuerzos que había hecho el Gobierno japonés hasta entonces por revertir los tratados desiguales sin éxito alguno, y que comenzaban a ver la necesidad de celebrar nuevos tratados con otras naciones en condiciones de igualdad. ${ }^{10}$

9. Ramírez Bonilla, 1996: 29.

10. Embajada de México en Japón, 2008: 16-18, passim. Cf. Ota Mishima, 1976. 
El ministro Ignacio Mariscal respondió que el Gobierno mexicano, encabezado en ese entonces por el porfirista Manuel González, sí estaría dispuesto a celebrar un tratado con Japón, aunque siendo conscientes de que los resultados prácticos en cuanto al comercio serían pocos, pero muy valioso como ejercicio de soberanía para ambas partes. No obstante el interés mutuo, hubo que esperar algunos años más, pues los esfuerzos japoneses en política exterior seguían enfocados en revertir de una sola vez los tratados desiguales. En 1886 culminó entonces la Conferencia Multilateral Preparatoria para la Revisión de Tratados con las Potencias Occidentales, cuyos resultados no fueron los esperados por Japón.

La firma de un tratado en condiciones de igualdad urgía al Gobierno japonés; fue así que el primer ministro Okuma Shigenobu enfocó esfuerzos en esta-

El año de 1867 representa un punto de inflexión en la evolución de dos países tan disímbolos como son México y Japón: en el primero, el gobierno constitucional de don Benito Juárez derrotaba a los grupos que sostuvieron el imperio de Maximiliano de Habsburgo; en el segundo, el feudalismo japonés tocaba a su fin con la caída del shogunato de Tokugawa. En ambos países se inauguró entonces una nueva era marcada por la realización de denodados esfuerzos para preservar la soberanía nacional y para modernizar las sociedades correspondientes blecer el postergado tratado con México. ${ }^{11}$ Las negociaciones se llevaron a cabo en Washington a través de los representantes de cada país. El Tratado de Amistad, Comercio y Navegación entre México y Japón fue firmado en Washington el 30 de noviembre de 1888, por Mutsu Munemitsu y por Matías Romero. En junio de 1889 entró en vigor en ambos países.

El artículo I de dicho Tratado establecía que habría "firme y perpetua paz y amistad entre los Estados Unidos Mexicanos y el Imperio del Japón y entre

11. Vázquez, 2000b: 91. Para más detalles sobre la negociación, véase: Kunimoto, 1975: 26-46. 
sus respectivos súbditos y ciudadanos", ${ }^{12}$ aspecto que se cumplió al menos durante el tiempo en que estuvo vigente este documento (en 1924 fue sustituido por un nuevo tratado). El artículo III establecía la "recíproca libertad de comercio y navegación".

El artículo IV fue quizá la mayor concesión hecha por Japón en este acuerdo, ya que permitía a los ciudadanos mexicanos "el privilegio de entrar, permanecer y residir" en cualquier parte del territorio japonés; éste era un derecho que no se le había otorgado a ninguna otra nación; los extranjeros que arribaban a Japón sólo tenían libre acceso a zonas específicas, como el puerto de Yokohama, por ejemplo. Aunque en un artículo secreto que se firmó por separado se reservó el derecho unilateral al emperador japonés de derogar las concesiones del artículo IV.

Quizá el artículo VIII fue el de mayor trascendencia para la parte nipona, ya que se eliminaba la extraterritorialidad jurídica que las potencias occidentales ejercían en Japón, pues los ciudadanos de tales potencias que residían en el archipiélago estaban exentos de someterse a las leyes niponas. Por primera vez Japón lograba firmar un tratado igualitario en este sentido, donde los mexicanos en aquel país tendrían que acatar la jurisdicción japonesa, así como los japoneses en México tendrían que acatar las leyes mexicanas. Ése fue el gran precedente que logró el Gobierno nipón para futuras negociaciones.

El siguiente paso que se dio rumbo a la consolidación de relaciones entre ambos países fue la instalación de representaciones diplomáticas. En 1891 José María Rascón presentó credenciales ante el emperador Meiji como enviado extraordinario y ministro plenipotenciario de México en Japón. A su vez, en 1892 Murota Yoshifumi hizo lo propio como representante del Gobierno japonés en México ante el presidente Porfirio Díaz. La oficina consular que se encargó de abrir Murota Yoshifumi fue el "primer establecimiento diplomático de su país en América Latina”. ${ }^{13}$ La instalación de ambas representaciones fue, desde luego, producto de la firma del Tratado de 1888.

\section{Los colonos japoneses de Chiapas}

Enomoto Takeaki, quien era el ministro de Asuntos Exteriores cuando se estableció la representación diplomática de Japón en México y viceversa,

12. SRE, 2000: 251-253, passim.

13. Embajada de México en Japón, 2008: 19. 
fue uno de los mayores promotores de la emigración japonesa, entendida en esos años finales del siglo XIX como una actividad económica alternativa y necesaria. Cuando dejó de formar parte del gabinete del Gobierno Meiji, puso en marcha sus ideas sobre el fomento de la emigración nipona hacia América Latina, en específico hacia México, y fundó una compañía de migración para tales fines. ${ }^{14}$

Tras una serie de gestiones necesarias (aunque insuficientes) realizadas tanto en México como en Japón, en marzo de 1897 salió del puerto de Yokohama el primer grupo migratorio japonés con destino a tierra mexicana. Estaba compuesto por 28 trabajadores que viajaban bajo el perfil de colonos, más otros seis como emigrantes libres. ${ }^{15}$ Un 10 de mayo de 1897 llegaron al puerto de San Benito, Chiapas (hoy conocido como Puerto Madero). De ahí iniciaron una penosa marcha bajo el calor y la humedad implacable que reina en esa zona del país. Recorrieron cerca de 130 kilómetros rumbo a las cercanías del pueblo de Escuintla, hasta llegar a los terrenos donde tenían que establecerse y trabajar.

La idea era que los colonos y los migrantes libres enviados por Enomoto cultivaran café, pero la época del año en que llegaron no era la ideal para iniciar esa tarea; tampoco los cafetos que consiguieron eran los correctos para sembrar en ese tipo de clima ni en la altitud en que se encontraban. En pocas palabras, contaban con escasa capacitación sobre el trabajo agrícola específico que tenían que hacer, sobre la tierra que estaban pisando, y un aspecto más en su contra: desconocían por completo el idioma castellano, lo cual los limitó en un principio para pedir auxilio a la población local.

Aquello pronto se convirtió en un infierno: sus reservas de alimentos comenzaron a escasear, vinieron las enfermedades propias del trópico, lluvias torrenciales, calores insoportables y la imposibilidad de sacar provecho a las tierras de la compañía colonizadora. Tres años después de haber llegado a México, el grupo migratorio se desintegró por completo.

Pero justo los seis migrantes libres, que eran jóvenes varones con estudios en agronomía, no se dieron por vencidos y decidieron fundar en Escuintla la Sociedad Cooperativa Japonesa Mexicana, liderada por Terui Ryojiro, y que según Makoto Toda y Shozo Ogino, "llegó a ser una de las mayores empresas de

14. Endoh, 2009: 63.

15. Ota Mishima, 1982: 42. 
capital japonés en manos de inmigrantes en todo el continente americano". ${ }^{16}$ Sin embargo, este fue un caso excepcional, pues a lo largo de la primera década del siglo xx se hablaría de nuevos proyectos de colonias japonesas en México, pero ninguno llegó a ejecutarse. No obstante, en esa misma década más de 10 mil migrantes japoneses desembarcarían en puertos mexicanos.

\section{Inmigrantes japoneses bajo contrato}

Ante nuevas concesiones otorgadas por el Gobierno porfirista para la explotación de minas y la construcción de ferrocarriles, las empresas requerían de mano de obra disponible, la cual no era fácil de obtener en México debido al sistema imperante del peonazgo, que tenía en condiciones de semiesclavitud a la mayoría del campesinado mexicano. Por ello se hizo necesario atraer trabajadores extranjeros para cubrir estas actividades; fue así como llegaron miles de chinos y japoneses en esa época.

Entonces se crearon en Japón tres compañías dedicadas a la contratación y transportación de los trabajadores japoneses: la Kumamoto Imin Kaisha, la Toyo Kisen Kaisha y la Tairiku Shokumin Kaisha. La mayor parte de ellos llegó para trabajar en la compañía del Ferrocarril Central, ${ }^{17}$ que principalmente los ocupó en labores de construcción de líneas férreas entre Manzanillo y Guadalajara; les sigue la mina de carbón Las Esperanzas, en Coahuila, y en tercer lugar, según Ota Mishima, en la plantación de caña de azúcar denominada La Oaxaqueña, ubicada en el cantón de Minatitlán, Veracruz. ${ }^{18}$

El primer grupo de japoneses que llegó a México para trabajar bajo contrato no vino de Japón, sino de Salt Lake City, Estados Unidos, para laborar en la mina Las Esperanzas. Se trató de 15 mineros que llegaron a principios de 1901. El buen desempeño de estos trabajadores hizo que la minera solicitara más obreros japoneses. Lo mismo ocurría en otras compañías donde eran contratados, y a pesar de su alta deserción, los empleadores seguían solicitando trabajadores oriundos de Japón. ${ }^{19}$

16. Toda, y Ogino, 2010: 69 .

17. Aunque Enrique Cortés afirma que la mayoría venía con destino al trabajo de las minas. Véase: Cortés, 1980: 96.

18. Ota Mishima, 1982: 56 y 57.

19. Sobre los japoneses provenientes de Salt Lake City: Yanaguida y Rodríguez del Alisal, 1992: 147. Sobre la valoración de los trabajadores japoneses, véase: Haro, et al., 2011: 141. 
Miles llegaron, y así se fueron. En general los japoneses no venían con la idea de quedarse en México, sino que su destino final en mente era Estados Unidos, donde se ofrecían mejores sueldos y mejores condiciones laborales. Además, precisamente las condiciones de trabajo existentes en México, que eran ínfimas tanto en la construcción ferrocarrilera como en las minas y en los cañaverales, eran poco aliciente para hacer que el trabajador japonés se quedara. Un ejemplo de esto nos lo relata Chizuko Watanabe:

Hay registros que demuestran que la vida de los inmigrantes en los lugares donde los contrataron estaba llena de miseria y dificultades. Poco después de su arribo, muchos enfermaban por no estar acostumbrados al clima tropical o del desierto, al trabajo pesado bajo el fuerte sol, el cambio de dieta, pobre nutrición, la mala calidad del agua y la falta de higiene en las viviendas. Como resultado de estas condiciones, beriberi, diarrea, tifoidea y malaria llegaron a ser incontenibles. ${ }^{20}$

Sumemos a lo anterior que las compañías de enganche les prometían mucho más de lo que en realidad ofrecían los contratos.

Tenemos que de los más de 10 mil japoneses que llegaron a México entre 1900 y 1910, sólo una cuarta parte permanecieron en este país al final de esa década. ¿A dónde se fueron? El historiador Moisés González Navarro, basado en notas de prensa de la época, escribió que "un gran número de japoneses y de chinos se encontraban en Ciudad Juárez en 1907, esperando una oportunidad para entrar a Estados Unidos". En lo anterior pudiéramos encontrar buena parte de la respuesta. ${ }^{21}$

Números. Según datos que ofrece Kunimoto Iyo Imura en su tesis doctoral Japan and México, 1888-1917 (University of Texas, 1975), 10,188 pasaportes fueron otorgados por el Gobierno Meiji para japoneses que viajarían a México entre los años 1901 y 1907; en ese mismo periodo las tres compañías antes mencionadas transportaron hacia suelo mexicano a 8,706 migrantes japoneses, siendo la Tairiku Shokumin Kaisha la más activa con 4,416 migrantes,

20. "Existent records show that the actual lives of immigrants in contracted locations were full of misery and hardship. Soon after their arrival, many fell ill because of the unaccustomed tropical or desert climate, hard work under the strong sun, change of diet, poor nutrition, the bad quality of water and unsanitary living quarters. As a result of these conditions, beriberi, diarrhea, typhoid, and malaria became rampant" (Watanabe, 1983: 24). Véase también: Masterson, Daniel y Funada-Classen, 2004: 31.

21. González Navarro, 1960: 84. 
y que fue la encargada de traer trabajadores para las obras del ferrocarril; le siguió la Toyo Kisen Kaisha, que transportó 3,048 migrantes destinados principalmente a las minas del norte del país, y por último la Kumamoto Imin Kaisha, con 1,232 trabajadores nipones. ${ }^{22}$

Enrique Cortés comparte que la agencia Kumamoto trajo a esos 1,232 migrantes en 12 grupos, o entiéndase 12 viajes marítimos: lo hizo entre noviembre de 1901 y octubre de 1907. Los japoneses traídos por la Toyo Kisen Kaisha también se dividieron entre 12, pero en un periodo menor: de junio de 1904 a octubre de 1907. La agencia Tairiku fue la que más migrantes trajo (incluidas poco más de 170 mujeres), en menos grupos y en menor tiempo, pues lo hizo entre noviembre de 1904 y mayo de $1907 . .^{23}$

A las cifras anteriores habría que sumar los japoneses que transmigraron desde Perú y Estados Unidos, así como los que hicieron el viaje desde Japón por su cuenta. Kunimoto Iyo Imura se aventura a decir que en ese periodo de 1901 a 1907 entre 11 mil y 12 mil japoneses pasaron por suelo mexicano. ${ }^{24}$ Probablemente quienes llegaban desde Estados Unidos venían tratando de dejar atrás alguna situación de persecución o maltrato. Para el caso de quienes dejaban Perú, aplica la misma razón, agregando que muchos abandonaron aquel país con la simple idea de alcanzar tierra estadounidense, convirtiéndose México en un paso intermedio.

De acuerdo con María Elena Ota Mishima, los principales puertos marítimos que recibieron a estos inmigrantes en esos años fueron: Manzanillo y Salina Cruz; los puertos de tierra que registraron entradas de japoneses fueron: Mexicali, Tijuana y Ciudad Juárez. Para la llegada de los japoneses provenientes de Perú, se apunta principalmente al puerto de Mazatlán. ${ }^{25}$ Hubo otros puertos mexicanos que también recibieron los pasos de los nipones, como Ensenada, Guaymas, y por raro que parezca, Veracruz. Es un hecho que los años de 1906 y 1907 fueron los de mayor actividad en cuanto al arribo de estos migrantes japoneses, en su mayoría jóvenes varones.

Los datos que al respecto arrojó el III Censo de Población de los Estados Unidos Mexicanos, efectuado en 1910, nos dicen que para ese año sólo había

22. Kunimoto, 1975: 68 y 69.

23. Cortés, 1980: 87 y 88.

24. Kunimoto, 1975: 69.

25. Ota Mishima, 1997: 105 y 106. Sobre los japoneses provenientes de Perú en Mazatlán, véanse: Cortés, 1980: 99 y 100; González Navarro, 1960: 84 y 85. Sobre los japoneses provenientes del Perú en general, véase: Masterson y Funada-Classen, 2004: 42. 
2,216 japoneses residiendo en México (de quienes 179 eran mujeres). Los números de dicho censo son útiles como una referencia, aunque no deben ser tomados como definitivos; lo más probable es que esa cantidad total se acerque a los tres mil individuos. Lo que sí es un hecho es que la gran mayoría de los que supuestamente venían a trabajar a México terminaron haciéndolo en Estados Unidos.

\section{Posibles causas de la emigración japonesa de finales del siglo xIX y principios del $\mathrm{xx}$}

Existen diversos aspectos para estudiar y comprender las causas que propiciaron que miles de japoneses dejaran su tierra para ir a un lugar totalmente desconocido para ellos. Varios de los autores consultados afirman que para la década de 1880 (misma en que fue firmado el tratado con México), dentro de la élite intelectual y política de Japón comenzaron a rondar propuestas discursivas a favor de la emigración como una solución al problema de la presión poblacional y la pobreza, ${ }^{26}$ reconociendo que en el archipiélago no existían las condiciones necesarias para resolver estos problemas. Entre 1880 y 1900 la población japonesa creció de 35 a 45 millones de habitantes. Había que mirar más allá de las fronteras, buscar lugares donde los desposeídos pudieran poseer y a la vez ayudar en el crecimiento económico del país con sus remesas.

Quizá sean dos las voces que destacaron en la promoción inicial de la emigración nipona. La primera: la del vizconde Enomoto Takeaki, quien no sólo veía a la emigración como una manera de relajar la presión demográfica, sino también como una herramienta para estimular la industria marítima, las exportaciones, y por ende, el crecimiento industrial en Japón. Planteaba las cosas como una especie de ganar-ganar: los migrantes se beneficiarían con mejores condiciones de vida y la nación con crecimiento económico. Enomoto señalaba a América Latina como un destino migratorio de gran potencial, pensaba sobre todo en México. La otra voz destacada en este tema fue Okuma Shigenobu, aquel que fuera primer ministro cuando se firmó el tratado con México. Él creía que en la era del liberalismo la migración era algo inevitable, que era una solución para aliviar lugares sobrepoblados, y a la vez servía para poblar grandes espacios ocupados por pocos habitantes. ${ }^{27}$

26. Gordon, 2009: 93.

27. Endoh, 2009: 62 y 63. 
Enfocándonos en Enomoto Takeaki, como ya se mencionó en párrafos previos, él era ministro de Asuntos Exteriores cuando se instaló la primera representación diplomática de México en Japón. Fue en esos inicios de la década de 1890 cuando Enomoto instituyó el Departamento de Migración. ${ }^{28}$ Por esos años los principales destinos migratorios promovidos fuera del archipiélago por el Gobierno imperial eran Taiwán y Corea. Por otra parte, el flujo de trabajadores nipones hacia Hawai y Estados Unidos (principalmente hacia el estado de California) comenzó a ser importante en números.

Luego vino la historia de los colonos enviados por Enomoto a Chiapas en 1897, aprovechando el tratado de 1888 y las buenas relaciones que se habían sostenido con el Gobierno de Porfirio Díaz desde entonces. Después de la apertura del destino mexicano se abrieron al menos dos más: Perú y Brasil. Las compañías privadas en Japón, especializadas en contratación y traslado de migrantes, ejercieron un rol muy importante en la migración japonesa con ruta a México, Perú y Brasil (en ese orden hasta 1910, año en que estalló la Revolución Mexicana; entonces los flujos migratorios japoneses hacia América Latina se enfocaron de manera importante en Brasil).

Según Andrew Gordon, para principios de la década de 1900, después de las exportaciones de té y seda, la tercera fuente de ingresos de divisas para Japón eran las remesas enviadas por los migrantes japoneses establecidos en Hawai, California y América Latina. ${ }^{29}$ No obstante las acciones de fomento institucional del Gobierno Meiji en esta materia, su actitud al respecto no fue tan clara y contundente comparada con las políticas ejecutadas en las décadas de 1920 y 1930, años en que el discurso migratorio estuvo acompañado por una política abiertamente imperialista.

En los años tempranos de la era Meiji, las políticas migratorias se enfocaron en desplazamientos internos, específicamente en promover el poblamiento de la isla norteña de Hokkaido, mientras que la migración más allá de las fronteras niponas no era aún prioridad, y la prueba está en que hasta antes de 1880 apenas unos mil japoneses se habían aventurado a viajar a Hawai para trabajar en campos de caña de azúcar. ${ }^{30}$

28. Kaibara, 2000: 264; Ota Mishima, 1982: 23.

29. Gordon, 2009: 94.

30. Sobre la migración interna como prioridad del gobierno Meiji en sus inicios, véanse: Endoh, 2009: 60 y 61; Mason y Caiger, 1997: 272. Sobre los japoneses que emigraron a Hawai antes de 1880: Masterson y Funada-Classen, 2004: 9. 
Sin embargo, para finales de la década de 1880 la cifra de japoneses en Hawai se incrementó a casi cinco mil, y unos mil más habían llegado a las lejanas costas de California. ${ }^{31}$ No obstante, eran números pequeños comparados con lo que vendría después. En unos pocos años estas cifras se dispararon y tenemos que para 1892 en Estados Unidos había ya cuatro mil 500 japoneses, y en Hawai unos 22 mil. ${ }^{32} \mathrm{Sin}$ duda el flujo migratorio hacia estos destinos se intensificó y para 1907 los japoneses en Hawai sumaban la cantidad de 65 mil, mientas que en tierras continentales de Estados Unidos alcanzaban ya los 60 mil, ${ }^{33}$ y agreguemos aquí otros miles más que habían llegado a México y Perú.

Además de las causas ya mencionadas de presión demográfica y pobreza (que hasta cierto punto eran argumentos retóricos), ¿qué propiciaría que para finales del siglo XIX y principios del xx miles de japoneses se volcaran a los navíos que iban rumbo a tierras desconocidas, muy lejos de su patria? Una primera pista está en la aplicación de políticas institucionales en este sentido, pero, ¿qué originó que el Gobierno Meiji comenzara a promover la emigración de japoneses?

Iniciemos por el hecho de la presión sociopolítica y económica que se disparó en las zonas rurales durante la década de 1880. Recordemos que en 1873 se introdujo un nuevo modelo recaudatorio en Japón, dentro del cual se instituyó un sistema de impuestos sobre la tenencia de la tierra, buscando el Gobierno Meiji equilibrar y racionalizar sus ingresos fiscales al eliminar los antiguos modos tributarios del shogunato Tokugawa, ${ }^{34}$ que ante los ojos de los políticos liberales era un sistema arbitrario.

Esta reforma afectó principalmente a los campesinos pobres, cuya producción en su mayoría era de subsistencia. El impuesto establecido tenía que ser pagado en efectivo (y no en especie como en el viejo sistema), mismo del que carecían dichos campesinos, obligándolos a entrar a un sistema de mercado en el que eran sumamente vulnerables, y que incluso llevó a muchos a perder sus tierras.

El fantasma de la inflación se hizo presente en esa década de 1880; el precio del arroz se incrementó considerablemente. De acuerdo con Mikiso Hane, el impuesto se calculaba en función al precio del arroz, y "en el año de

31. Gordon, 2009: 118; Akira, 1989: 759.

32. Akira, 1989: 762.

33. Gordon, 2009: 118.

34. Endoh, 2009: 65; Vlastos, 1989: 378. 
1884 los campesinos tuvieron que entregar $32.8 \%$ de su cosecha en concepto de impuestos", más del doble de lo que habían pagado en $1881 .{ }^{35}$

El Gobierno Meiji reaccionó aplicando políticas antiinflacionistas propuestas por el ministro de Hacienda, Matsukata Masayoshi. Los "remedios" agravaron la enfermedad. Los ingresos generados por productos agrícolas cayeron aún más y las deudas de los campesinos aumentaron. Mikiso Hane afirma que "en 1885, más de cien mil familias encontraron la ruina" ${ }^{36}$ Hay quien dice que $10 \%$ del total de los campesinos independientes perdieron sus tierras. Daniel M. Masterson nos ofrece unas cifras del año 1895 que nos indican que las cosas poco o nada mejoraron en la década siguiente: "Sólo en $1895,108,000$ granjas cayeron en bancarrota y 400,000 campesinos perdieron sus medios de vida". ${ }^{37}$

Muchos de estos desposeídos migraron internamente a los nuevos centros industriales para emplearse como obreros; otros encontraron una manera de subsistir en la minería reactivada por esos años. Pero aquellos que no encontraron el modo de hacer una vida en su propio país optaron por oír el llamado del Estado y de las compañías contratistas que los invitaban a salir de Japón.

La gran mayoría de esos emigrantes japoneses de finales del siglo XIX y principios del xx eran hombres jóvenes. Una de las varias causas que delinearon este perfil tiene que ver con el establecimiento del servicio militar obligatorio, decretado por el emperador Meiji en 1873. Este decreto ordenaba que los varones de 20 años de edad tuvieran que hacer el servicio militar durante tres años. De inicio dicha disposición fue por demás antipopular. ${ }^{38}$

Emigrar fue una manera que encontraron muchos jóvenes para evitar los campos marciales. Principalmente se iban a esos primeros destinos que fueron Hawai y California, y más adelante, quizá, México y Perú. Incluso la emigración hacia territorios ganados militarmente por la armada japonesa, como Taiwán, Corea y Manchuria, irónicamente sirvieron como destinos a muchos jóvenes migrantes que buscaban evitar el servicio militar. ${ }^{39}$

35. Mikiso, 2003: 118.

36. Mikiso, 2003: 136; cf. Vlastos, 1989: 419; Mason y Caiger, 1997: 290.

37. "In 1895 alone, 108,000 farms went into bankruptcy and 400,000 peasants lost their means of making a living" (Masterson y Funada-Classen, 2004: 8). A su vez cita a: James Stanlaw, "Japanese Emigration: From Meiji to Modern Times", American Antropological Association anual meeting, Nueva Orleans, 21 nov., 2002.

38. Gordon, 2009: 66.

39. Endoh, 2009: 62. 
Entre 1894 y 1895 Japón y China chocaron bélicamente por el control de la península de Corea, fue el primer gran reto militar del Gobierno Meiji, el cual superó al hacerse de la victoria. ${ }^{40} \mathrm{Al}$ finalizar dicha guerra, muchos de los jóvenes campesinos que habían sido enrolados para combatir y que regresaron con vida a su tierra fueron liberados del servicio marcial. Esto significaba que regresaban del infierno de la guerra a la realidad cotidiana donde no tenían tierra qué cultivar o alguna otra oportunidad dónde emplearse y ganarse la vida. La emigración se les presentó entonces como una opción latente. ${ }^{41}$

Un aspecto más que delineó — al menos hipotéticamente- el perfil del migrante joven, de sexo masculino y de origen campesino, fue la imposición del mayorazgo a partir de 1898, que se estipuló dentro del Código Civil diseñado por el Gobierno Meiji. ${ }^{42}$ El mayorazgo es aquella práctica donde el primer hijo varón (primogénito), por ese simple hecho tiene el derecho por encima de los demás miembros de su familia, de heredar y administrar los bienes familiares, y aún más, de convertirse en patriarca de la familia.

De acuerdo con Mikiso Hane, en Japón el mayorazgo se volvió "obligatorio para todas las clases sociales"; entonces el jefe de familia adquirió el "derecho a controlar las propiedades familiares, decidir el lugar de residencia de todos sus miembros y aprobar o no divorcios y matrimonios". ${ }^{43}$ ¿Qué tiene que ver la imposición del mayorazgo con el tema migratorio? La respuesta nos la ofrece Toake Endoh:

[...] un amplio número desproporcionado de hijos segundos y terceros de familias agrarias migraron a América Latina, y más tarde, a Manchuria. Esos jóvenes marginados y sin esperanza vislumbraron una vida con oportunidades en nuevos mundos, siguiendo un sueño que ya no era posible en casa $[\ldots]^{44}$

Entre 1904 y 1905 sucedió la guerra ruso-japonesa, de la cual Japón salió victorioso; sin embargo, fueron decenas de miles las vidas sacrificadas y demasiados los recursos materiales que se derrocharon. Al terminar la guerra

40. Gordon, 2009: 116; Mikiso, 2003: 154 y 155.

41. Masterson y Funada-Classen, 2004: 16.

42. Mikiso, 2003: 148.

43. Ídem; Yanaguida y Rodríguez del Alisal, 1992: 289-293 y 299.

44. ".. a disproportionately larger number of the second and third sons of agrarian families migrated to Latin America and, later, Manchuria. Those marginalized and hopeless youngsters sought life opportunities in new worlds, pursuing a dream that was not possible at home..." (Endoh, 2009: 62). 
la situación de buena parte de los combatientes triunfantes fue similar a la de aquellos de la guerra sino-japonesa; a pesar del orgullo de la victoria, regresaban a una realidad cotidiana poco esperanzadora. Fue así como muchos de estos combatientes desocupados, a través de agencias de contratación, llegaron al continente americano en busca de oportunidades laborales, muchas de ellas ilusorias. ${ }^{45}$

Así, una serie de aspectos generales estaban puestos sobre la mesa para que miles y miles de japoneses salieran de su país en búsqueda de mejores oportunidades, aunque eso sí, siempre con la esperanza de volver, hecho que muy pocos lograron. Ante esas causas generales, es justo decir que también estaban aquellas razones diversas, y quizá innumerables, que existieron en la mente de cada individuo que decidió embarcarse y cruzar vastos mares.

Sobre la nación mexicana como destino migratorio, tenemos que, si Japón necesitaba generar un flujo emigratorio, México deseaba uno inmigratorio. Mientras Japón padecía presión demográfica, a México en teoría le sobraba terreno para recibir huestes de nuevos habitantes. Desde los primeros años como nación independiente, el Estado mexicano sabía de la necesidad de atraer migración extranjera como una medida urgente para poblar zonas deshabitadas del país y que estaban en constante acecho por las potencias extranjeras. Cuando México fue despojado de la mitad de su territorio a raíz de la separación de Texas y la invasión estadounidense, se perdieron muchísimos kilómetros cuadrados pero muy pocos habitantes.

Sin embargo, colonizar era costoso y el Gobierno mexicano no tenía dinero ni para lo básico y, aún más, la guerra y el desorden eran lo cotidiano, y a ningún migrante le atrae esa cotidianidad. Fue en los tiempos del Porfiriato (1876-1911) cuando las condiciones se produjeron para ejecutar planes de inmigración; el Gobierno porfirista parecía estar de acuerdo en que vinieran migrantes extranjeros a México, pero invirtiendo poco o nada en su instalación. ${ }^{46}$

45. Sobre la guerra ruso-japonesa: Mikiso, 2003: 157-159; Gordon, 2009: 119. Sobre los migrantes excombatientes: Cortés, 1980: 99 y 100; Kaibara, 2000: 264; Watanabe, 1983: 11.

46. Según el historiador Moisés González Navarro, el problema en México no era la falta de población, sino la mala distribución de la misma y el sistema imperante del latifundismo. La paradoja de la política poblacional del Porfiriato fue que el número de mexicanos que emigraron a Estados Unidos como braceros fue mucho mayor que la cantidad de inmigrantes extranjeros que vinieron a trabajar a México. González Navarro, 1960: 1-105 y 147. 
En el caso de los japoneses, ya apuntamos que la colonia nipona en Chiapas fue algo excepcional. Lo que siguió fueron esos miles de braceros con contrato, que en su mayoría venían con la ilusión de "dar el salto" a Estados Unidos. El acarreo transoceánico de estos trabajadores significó un gran negocio para las compañías contratistas japonesas, que en muchos casos operaron con pocos escrúpulos, a la vez que sacaban provecho de toda la permisividad necesaria de los gobiernos de Japón y México. Sin embargo, después de más de 10 mil inmigrantes japoneses, el límite llegó.

\section{Cierre oficial del flujo migratorio japonés hacia México}

La migración japonesa hacia Estados Unidos comenzó a tomar un tono color problema. En California se desataron acciones oficiales antijaponesas tales como prohibir a los nipones poseer tierras; en San Francisco se llegó al extremo de no permitir en las escuelas la asistencia de niños japoneses. Al Gobierno estadounidense le preocupaba que las decenas de miles de inmigrantes de Japón fueran una avanzada "imperialista" silenciosa, ya que el triunfo japonés de 1905 en la guerra ruso-japonesa consolidaba al imperio del sol naciente como una potencia internacional; no en vano ese mismo año Estados Unidos y Japón firmaron un acuerdo donde los primeros reconocían los intereses del otro en Corea, mientras que el imperio nipón reconocía los intereses de los estadounidenses en Filipinas.

Para que el tema migratorio no fuera un punto de disputa entre ambas naciones, éstas establecieron en 1907 un Gentlemen's Agreement (pacto de caballeros) donde Japón se comprometía a no incentivar más la migración hacia Estados Unidos ni a sus naciones vecinas: Canadá y México. Justo en ese año de 1907 llegó el último gran contingente de braceros japoneses a México, y para 1908 las cifras de arribos disminuyeron notablemente: Japón había dejado de autorizar pasaportes a los súbditos con destino mexicano.

Por su parte, el Gobierno mexicano también desalentó este flujo migratorio, en buena medida por presión de Estados Unidos, pues era innegable que una cantidad considerable de los inmigrantes ilegales que llegaban a la nación de la bandera de las barras y las estrellas, entraban por la frontera mexicana. ${ }^{47}$

47. Para más detalles sobre este aspecto, véanse: Yanaguida y Rodríguez del Alisal, 1992: 60-70, 75-76, 154-156; Cortés, 1980: 100-103. También: Masterson y Funada-Classen, 2004: 108; Haro, et al., 2011: 143. Vid. Akira, 1989: 778 y 779. 
En marzo de 1909 entró en vigor la Ley de Inmigración en México. Aunque esta ley no mencionaba nacionalidades, de algún modo discriminaba el ingreso de asiáticos al país, ya que prohibía la entrada a personas con enfermedades que en ese entonces azotaban al Este asiático, incluido Japón. De cualquier forma el arribo de japoneses a México continuó, pero en números marcadamente menores comparados con los de 1906 y 1907, y que provenían de Estados Unidos y Perú, países donde empezaban a sufrir discriminación racial. Terminó así, casi al cierre de esa década, lo que pudiéramos denominar la "época de oro" de la inmigración japonesa en México.

\section{Los migrantes japoneses que llegaron a Guadalajara durante el Porfiriato}

Los casos específicos que se mencionan a continuación son apenas los primeros hallazgos de una investigación inacabada. Tómese como tal. Es un adelanto de los primeros pasos dados dentro de este tema específico. Es por ello también que se ha omitido ofrecer conclusiones al final sobre esta parte del texto. Por lo pronto lo que importa al autor del presente artículo es dar a conocer la información hasta ahora encontrada.

De esos miles de japoneses que pasaron por México en la primera década del siglo $\mathrm{xx}$, hubo unos cuantos que decidieron quedarse, al menos por un tiempo, en el estado de Jalisco, específicamente en Ciudad Guzmán, Tuxpan y Guadalajara. En su mayoría se trató de aquellos que atravesaron el océano Pacífico con un contrato para trabajar en la compañía del Ferrocarril Central, en varios ramales de la ruta Colima-Guadalajara. Estos trabajadores fueron traídos por la agencia Tairiku; se habla de al menos mil japoneses para esas obras, ${ }^{48}$ aunque la historia de deserciones en masa fue la misma.

Según Toshio Yanaguida y Dolores Rodríguez, 95\% de los migrantes nipones fueron abandonando las obras. Por un lado, por no soportar las condiciones del clima, de hacinamiento y mala higiene en las viviendas asignadas, aspectos ya mencionados en páginas anteriores; al respecto, el académico Pablo Serrano Álvarez escribió lo siguiente:

Los galerones que servían de habitación eran de madera, con techos de paja, carecían de ventanas, y se hacinaban en grupos de entre 20 y 30 personas.

48. Yanaguida y Rodríguez del Alisal, 1992: 152, passim. 
Las condiciones de los migrantes eran pésimas, las enfermedades y muertes abundaron $[\ldots]^{49}$

Por otro lado estaba el hecho de que los inmigrantes ya tenían en mente llegar y establecerse en Estados Unidos. En el camino muchos terminaron quedándose en otras partes del país, como Guadalajara y Chihuahua. Llaman la atención aquellos que prefirieron quedarse cerca de la zona de las obras para las que fueron contratados, como el poblado de Tuxpan, o Ciudad Guzmán.

En el caso de Guadalajara, Toshio Yanaguida y Dolores Rodríguez nos dicen que alrededor del año 1908 había en esta ciudad cerca de 200 japoneses. ${ }^{50}$ Dicha cifra parece exagerada, aunque si pensamos que sólo estuvieron de paso, en estancia corta, quizá a la espera de reunir recursos para seguir su camino hacia el norte, entonces no resulta tan descabellado ese número. No obstante, los datos duros y fríos del no tan confiable censo de 1910 nos dicen que para dicho año sólo había 14 japoneses en Jalisco, de quienes al menos 10 residían en Guadalajara.

¿Quiénes eran esos japoneses que llegaron a Guadalajara en aquellos años porfirianos? Recordemos, en el censo de 1910 se tienen registrados 14 japoneses en Jalisco (todos hombres), de quienes al menos 10 vivían en esta ciudad. De esos 10, sólo teníamos conocimiento del nombre de dos: Minakata Yusaburo y Yamashita Alfonso. Al inicio de la investigación, de la que es producto el presente texto, era lo único que se sabía al respecto. ${ }^{51}$

Ahora, después de realizar algunas búsquedas de archivo, se ha ampliado la lista a 13 nombres de migrantes japoneses — que radicaban en Guadalajara en 1911-, los cuales se presentan a continuación:

- Fukushima Hoorin.

- Inami Kooshoo.

- Hamada Shuichi.

- Katsumoto Tadao.

- Kuchiki Tasaburo.

- Marui Jiro.

49. Serrano Álvarez, 1998: 37.

50. Yanaguida y Rodríguez del Alisal, 1992: 152.

51. El texto que sirvió como punto de partida para esta investigación fue el trabajo de María Elena Ota Mishima titulado Siete migraciones japonesas en México: 1890-1978, publicado por primera vez en 1982 por El Colegio de México. Sobre los datos del censo de 1910, véase: Dirección General de Estadística, 1918: 161 y 199. 
- Minakata Yusaburo (Jesús Minakata).

- Samba Teiji.

- Shinno Goro.

- Takagi Munahachi.

- Yamaguchi Yutaro.

- Sanshiro Ninoi (o Arnulfo Nii).

- Yamashita Alfonso.

Quitando el último nombre de la lista, el resto fueron encontrados en un expediente ubicado en el Archivo Histórico del Estado de Jalisco, en la sección "Pasaportes y salvoconductos" del ramo Gobernación. Dicho expediente se refiere al encarcelamiento que sufrió Sanshiro Ninoi (penúltimo nombre de la lista) a mediados de 1911, quien era chofer y atropelló accidentalmente a un jovencito de 13 años de edad, que para peor suerte del japonés, el atropellado era hijo del jefe político del cantón de Guadalajara. El documento donde aparecen los nombres de dichos inmigrantes es una carta que enviaron a la Legación japonesa en ciudad de México pidiendo a su representante diplomático que intercediera por su compatriota Sanshiro.

A los nombres anteriores podríamos agregar algunos más:

- Fumakosi Mijume, Carlos.

- Shino Sakoda, Francisco.

- Shiraishi Shiraishi Matsujira.

- Tanaka, Alfredo.

- Tanaka Mago Siro Igua Magokichi.

- Watanabe Okane, Francisco.

- Yasukano Yakabi, Miguel.

La anterior es una lista aparte porque no hay certeza de que esos japoneses vivieran en Guadalajara en el periodo que persigue este proyecto (1897-1911). Tales nombres fueron tomados de registros oficiales hechos a inicios de la década de 1930; esos siete nipones radicaban en la capital de Jalisco cuando se hicieron dichos registros, pero declararon haber ingresado al país entre los años 1900 y 1910 (la mayoría lo hizo en 1907), varios de ellos por el puerto de Manzanillo.

Sobre los nombres que aparecen en el primer listado, podemos ampliar alguna información sobre cuatro de ellos. Alfonso Yamashita fue mecánico en los talleres de Ferrocarriles Nacionales, esto de acuerdo con María Elena 
Ota Mishima, quien a su vez extrajo esa información del expediente de naturalización de Yamashita, que data del año 1925 y se conserva en el Archivo Histórico de la Secretaría de Relaciones Exteriores. Al parecer este japonés llegó al país en 1908, y ese dato nos ayuda a deducir que Alfonso Yamashita no vino mediante las compañías contratistas ya mencionadas.

Luego tenemos el caso peculiar de Hamada Shuichi, quien al parecer era boxeador profesional, esto de acuerdo con una nota de prensa publicada el 30 de marzo de 1911 en el bisemanario tapatío El Kaskabel [sic.], que dice lo siguiente:

[...] nos parecía inconveniente que algunos alumnos de la Escuela de Artes, militarmente uniformados, hubieran servido de mozos en la lucha que como espectáculo público dieron el Bull-Dog y el japonecito Hámada [sic].52

No se puede asegurar aún, con total certeza, que Hamada Shuichi y "el Hamada" de la nota de prensa citada sean la misma persona, pero pudiéramos intuir que sí lo es, empezando porque el año de la nota y el año del expediente donde se descubre su nombre, es el mismo.

Pasemos ahora al caso de Sanshiro Ninoi, quien ante los mexicanos se hizo llamar Arnulfo Nii. Ya se comentó brevemente, en líneas anteriores, el accidente del cual fue partícipe; por los expedientes que se conservan de ese suceso, ocurrido en junio de 1911, conocemos del paso de Ninoi en Guadalajara, así como de los otros japoneses enlistados. Sanshiro Ninoi es descrito en tales documentos como "hijo de Sanouche Nii y de Kameltio [sic.] Nii, estatura baja y complexión robusta, color trigueño, ojos, pestañas y cejas negras, nariz regular, boca chica [...] y es de nacionalidad japonesa". ${ }^{53}$

Declaró ser "mayor de edad [tenía 20 años en 1911], soltero, mecánico originario del Japón y vecino de esta ciudad, con domicilio en la casa marcada con el número 312 de la calle de López Cotilla". Sanshiro Ninoi trabajaba como chofer del señor José Cortés, quien al parecer era un hombre acaudalado de

52. El Kaskabel. Bisemanario Humorístico, Guadalajara, marzo 30 de 1911, t. III, núm. 447, p. 2. El ejemplar consultado de esta publicación se conserva en un expediente del Archivo del Supremo Tribunal de Justicia del Estado de Jalisco, el cual forma parte de los acervos documentales conservados por la Biblioteca Pública del Estado de Jalisco. La referencia provisional del expediente es: ramo Criminal, año 1910, caja 20, exp. $18 \mathrm{ca}$. Consultado en febrero de 2012.

53. Biblioteca Pública del Estado de Jalisco, Archivo del Supremo Tribunal de Justicia del Estado de Jalisco, ramo Criminal, año 1910, caja 35, exp. 25; 36 ff. [Referencia provisional], passim. 
la Guadalajara de esa época. El domicilio que señala Ninoi es en sí el de don José Cortés. Llama la atención que la firma de este japonés sea en escritura alfabética y con buena caligrafía, lo que nos puede indicar que para ese año de 1911 tenía ya cierto tiempo radicando en México — que sabía castellano-, o podemos considerar también que fue de los japoneses que llegaron de Perú.

Por último tenemos el caso destacado de Minakata Yusaburo, también conocido como don Jesús Minakata. A él podemos considerarlo como el primer inmigrante japonés que se estableció en Guadalajara en la época del Porfiriato, o al menos dentro de lo que se tiene registro. Su caso merece sin duda una investigación aparte. Él mismo se encargó de dejar testimonio de algunos datos biográficos en sus Discursos familiares, impresos en 1955. Ahí narra lo siguiente:

\begin{abstract}
Allá por el año de 1901 llegué a estas tierras, sin más recursos que un deseo muy grande de trabajar y una fe inquebrantable en el triunfo. Nada de extraño tiene pues, que mis sufrimientos y privaciones hayan sido muchos, por mi pobreza y el absoluto desconocimiento de vuestro hermoso idioma. ${ }^{54}$
\end{abstract}

En esos recuerdos que compartió don Jesús Minakata ya en la vejez, cuenta que nació el 7 de noviembre de 1879 en un pueblo llamado Mikazura, "que pertenece al municipio de Nagasagun", en la prefectura de Wakayama; fue tercer hijo de Minakata Siroemón y de Minakata Yoshie. A los 17 años de edad decidió emprender el viaje a América; durante tres años y medio trabajó en plantaciones de California. ${ }^{55}$

Después decidió aventurarse hacia México, cruzó la frontera por El Paso, Texas. Llegó a Guadalajara en 1901. En esos años porfirianos sobrevivió trabajando como carpintero: hacía muebles de bambú al estilo japonés. Pronto se enamoró de una joven jalisciense llamada Micaela González, con quien se casó en el otoño de 1904. Para 1911 esta pareja ya tenía cuatro hijos —de los 10 que tuvieron en total. ${ }^{56}$

Con excepción de Alfonso Yamashita y Jesús Minakata, es probable que los demás que aparecen en la primera lista hayan huido a otra parte del país (o del país mismo) cuando la violencia desatada por la Revolución Mexicana alcanzó al estado de Jalisco; o quizá siguieron el curso migratorio hacia Estados

54. Minakata, 1955: 8.

55. Minakata, 1955: 47-57, passim.

56. Minakata González, 1998: 17. 
Unidos. En realidad cualquier conjetura aún no es posible comprobarla, pero sin duda resultaría interesante saber qué pasó con estos personajes oriundos de la tierra del sol naciente que estuvieron en Guadalajara en los últimos años del Porfiriato. Queda entonces mucho por investigar.

\section{Algunas conclusiones generales}

El Tratado bilateral firmado entre México y Japón en 1888 pudiera simbolizar el encuentro de dos naciones envueltas en procesos históricos paralelos con aspectos parecidos, ello durante la segunda mitad del siglo XIX. El establecimiento oficial de relaciones entre estos dos países permitió que ambos gobiernos apoyaran y promovieran la inmigración de japoneses a México, comenzando por la colonia establecida en Chiapas en 1897, y continuando con el arribo de miles de nipones, quienes viajaron con muchas ilusiones, entre ellas no permanecer en México sino terminar su viaje en Estados Unidos.

El perfil del migrante japonés en México entre 1897 y 1911 era de tipo masculino, jóvenes solteros en su mayoría y provenientes de áreas rurales de Japón. Las posibles causas generales que hicieron que dejaran su país fueron: políticas oficiales del Gobierno japonés que fomentaban la emigración bajo el pretexto de la alta densidad demográfica y la pobreza imperante en el archipiélago; la crisis en el campo provocada por las reformas fiscales del Gobierno Meiji; el decreto del servicio militar obligatorio, el cual muchos jóvenes buscaron evitar mediante la emigración; la guerra sino-japonesa (18941895) y la guerra ruso-japonesa (1904-1905) dejaron miles de combatientes sobrevivientes desocupados y sin medios para ganarse la vida al finalizar tales guerras; y la imposición legal del mayorazgo en 1898, que limitó las oportunidades de crecimiento económico para muchos jóvenes.

La gran mayoría de los inmigrantes nipones que vinieron a México entre 1901 y 1907 fueron enganchados en Japón por compañías contratistas, las cuales se encargaron de transportarlos hasta los centros de trabajo donde eran requeridos, destacando minas de carbón al norte mexicano, la construcción de ferrocarriles en el occidente, y los cañaverales al oriente. Así, durante la primera década del siglo xx más de 10 mil japoneses pisaron tierra mexicana, la mayor cifra en la historia de la inmigración japonesa en México. Dicha historia es un tema que no ha sido aún lo suficientemente estudiado. Esperemos sirva este texto como una invitación a la búsqueda de nuevas aportaciones en esta materia. ny 


\section{Referencias bibliográficas}

Akira, Iriye (1989), “Japan's drive to great-power status", en Jansen, Marcus B. (ed.), The Cambridge History of Japan, Volume 5: The Nineteenth Century, Nueva York: Cambridge University Press, pp. 721-782.

Asiain, Aurelio (2011), "Un mundo de rocío"; Letras Libres (revista mensual), núm. 149, mayo, México, DF: Vuelta, pp. 16-21.

Bartra, Armando (octubre, 2000-marzo, 2001), “Teoría y práctica del racismo. Plantaciones y monterías en el Porfiriato”; Ciencias, núm. 60-61; México, DF: UNAM-Facultad de Ciencias, pp. 72-79.

Beasley, W. G. (1989), "The foreign threat and the opening of the ports", en Jansen, Marcus B. (ed.), The Cambridge History of Japan, Volume 5: The Nineteenth Century, Nueva York: Cambridge University Press, pp. 259-307. Clements, Jonathan (2010), Los samurais. Historia y leyenda de una casta guerrera (trad. Cecilia Belza y Gonzalo García), Barcelona: Crítica, pp. 311-329.

Cortés, Enrique (1980), Relaciones entre México y Japón durante el Porfiriato, México, DF: Secretaría de Relaciones Exteriores-Archivo Histórico Diplomático Mexicano, pp. 1-9, 32-102.

Díaz, Lilia (2000), "El liberalismo militante", Historia general de México, versión 2000, 11 ${ }^{\mathrm{a}}$ reimpresión, México DF: El Colegio de México-Centro de Estudios Históricos, pp. 583-631.

Dirección General de Estadística (1918), III Censo de Población de los Estados Unidos Mexicanos, Verificado el 27 de octubre de 1910, vol. I, México: Oficina Impresora de la Secretaría de Hacienda-Departamento de Fomento.

Durán de la Torre, Ana Lilia (2009), Catálogo del asunto "Pasaportes y Salvoconductos", Ramo Gobernación del Archivo Histórico de Jalisco, 1876-1910, tesis para obtener el grado de licenciado en Historia, Guadalajara, México: Universidad de Guadalajara.

EJM (2010), Separata, México, DF: Embajada de Japón en México/Cámara Japonesa de Comercio e Industria de México/Asociación México-Japonesa.

Embajada de México en Japón (2008), Del Tratado al Tratado. 120 años de relaciones diplomáticas entre México y Japón: 1888-2008, 2ª edición (bilingüe), Tokio: Embajada de México en Japón.

Endoh, Toake (2009), Exporting Japan: Politics of Emigration to Latin America, Champaign, Estados Unidos: University of Illinois Press.

González Navarro, Moisés (1960), La colonización en México, 1877-1910, México, DF: Talleres de Impresión de Estampillas y Valores, pp. 1-105. 
González, Luis (2000), "El liberalismo triunfante”, Historia general de México, versión 2000, 11ª reimpresión, México, DF: El Colegio de México-Centro de Estudios Históricos, pp. 633-673.

Gordon, Andrew (2009), A Modern History of Japan. From Tokugawa Times to the Present, $2^{\mathrm{a}}$ edición, Nueva York: Oxford University Press, pp. 35-160.

Haro, Francisco Javier, José Luis León, y Juan José Ramírez (2011), Historia de las relaciones internacionales de México, 1821-2010. Volumen 6: Asia, en De Vega, Mercedes (coord.), México, DF: Secretaría de Relaciones ExterioresDirección General del Acervo Histórico Diplomático, pp. 117-150.

Hernández Ponce, Manuel Alejandro (2009), "Fugitivos tapatíos". Súbditos del Eje en Guadalajara durante la Segunda Guerra Mundial, tesis para obtener el título de licenciado en Historia, Guadalajara, México: Universidad de Guadalajara.

Hisashi, Ueno (autor), Konohana Sakuya (caricaturista) (ca. 2009), Los samuráis de México. La verdadera historia de los primeros inmigrantes japoneses en Latinoamérica [manga]; Koji Hashimoto (et al., trad.), [s. l. ed.], Kyoto: Seika University Business Promotion Section/Kyoto International Manga Museum/Asociación México-Japonesa, A. C.

Hugo, Diego (ed. y pról.) (2008), Viaje a Japón. Francisco Díaz Covarrubias, México, DF: Ediciones de Educación y Cultura.

Inazo, Nitobe (ed.) (2006), El Bushido. El alma de Japón, Barcelona: José J. de Olañeta.

INM (1996), “Ley de Inmigración, 1909”, Compilación histórica de la legislación migratoria en México, $1^{\text {a }}$ reimpresión, Instituto Nacional de Migración, México, DF: Segob-Instituto Nacional de Migración, pp. 1-16. (2002), "Ley de Extranjería y Naturalización, 1886", Compilación histórica de la legislación migratoria en México, 1821-2002, Instituto Nacional de Migración, México, DF: Segob-Centro de Estudios Migratorios, pp. 91-101. Jansen, Marius B. (1989), “The Meiji Restoration”, en Jansen, Marcus B. (ed.), The Cambridge History of Japan, Volume 5: The Nineteenth Century, Cambridge University Press, pp. 308-366.

Kaibara, Yukio (2000), Historia del Japón, México, DF: Fondo de Cultura Económica, pp. 1-266.

Kunimoto, Iyo Iimura (1975), Japan and México, 1888-1917, tesis doctoral, Austin: The University of Texas, pp. 1-98. 
Martínez Legorreta, Omar (1991), "De la modernización a la guerra", en Toledo B., J. Daniel, et al., Japón: Su tierra e historia, México, DF: El Colegio de México-Centro de Estudios de Asia y África, pp. 173-212.

Mason, Richard, y John Caiger (1997), A History of Japan, $5^{a}$ reimpresión de la edición revisada, Singapur: Tuttle Publishing, pp. 257-303.

Masterson, Daniel M., y Sayaka Funada-Classen (2004), The Japanese in Latin America, Champaign, Estados Unidos: University of Illinois Press, pp. I-XVIII, 1-111.

Michiko, Tanaka (1987), Cultura popular y Estado en Japón, 1600-1868. Organización de jóvenes en el autogobierno aldeano, México, DF: El Colegio de México, pp. 9-37, 127-155.

- - (1991), "De los orígenes a la caída del Shogunato Tokugawa", en Toledo B., J. Daniel, et al., Japón: Su tierra e historia, México, DF: El Colegio de México-Centro de Estudios de Asia y África, pp. 63-172.

Mikiso, Hane (2003), Breve historia de Japón, Madrid: Alianza Editorial, pp. 100-166.

Minakata González, Carlos (1998), Semblanza y anécdotas familiares de Jesús Yusaburo Minakata Minakata y Micaela González de Minakata, Guadalajara: Alfonso Nuño Rodríguez.

Minakata, Jesús (1955), Discursos familiares, Guadalajara [s. r. ed.].

Moreno Corral, Marco Antonio (2001), Odisea 1874 o el primer viaje internacional de científicos mexicanos, $3^{\mathrm{a}}$ edición, México, DF: Fondo de Cultura Económica.

Ogino Fujioka, Shozo (2010a), "Viaje de la Comisión Astronómica Mexicana al Japón. Antecedente de la negociación del Tratado de Amistad y Comercio"; Separata, México, DF: Embajada de Japón en México/Cámara Japonesa de Comercio e Industria de México/Asociación México-Japonesa, pp. 43-47. (2010b), "Desde la concertación del Tratado hasta el centenario de la Independencia de México", Separata, México, DF: Embajada de Japón en México/Cámara Japonesa de Comercio e Industria de México/Asociación México-Japonesa, pp. 49-63.

Ota Mishima, María Elena (1982), Siete migraciones japonesas en México: 1890 1978, $1^{a}$ reimpresión, México, DF: El Colegio de México.

Ota Mishima, María Elena (coord.) (1997), Destino México. Un estudio de las migraciones asiáticas a México, siglos XIX y XX, México: El Colegio de MéxicoCentro de Estudios de Asia y África, pp. 11-18, 55-121. 
Ota Mishima, María Elena (Introducción, selección y notas) (1976), México y Japón en el siglo XIX: La política exterior de México y la consolidación de la soberanía japonesa, México, DF: Secretaría de Relaciones Exteriores, Col. del Archivo Histórico Diplomático, Serie Documental, núm. 14, pp. 1-27. Ramírez Bonilla, Juan José (1996), Población y políticas sociales en Japón y México: 1870-1990, México, DF: El Colegio de México, pp. 1-71.

Romero Estrada, Francisco A. (2000), "Factores que provocaron las migraciones de chinos, japoneses y coreanos hacia México: Siglos XIX y XX. Estudio comparativo"; Revista de Ciencias Sociales, IV(90-91), San José, Costa Rica: Universidad de Costa Rica, pp. 141-153.

Salazar, Delia (2010), Las cuentas de los sueños. La presencia extranjera en México a través de las estadísticas nacionales, 1880-1914, México, DF: Instituto Nacional de Migración/Instituto Nacional de Antropología e Historia, pp. 1-143, 275-301, 361-462.

Santa Cruz, Arturo (2000), Un debate teórico empíricamente ilustrado: La construcción de la soberanía japonesa, 1853-1902, Guadalajara, México: Universidad de Guadalajara.

Secretaría de Fomento, Colonización e Industria (1910), Estadística de inmigración formada por la Dirección General de Estadística a cargo del Dr. Antonio Peñafiel, núm. 1, año de 1909, México, DF: Imprenta y Fototipia de la Secretaría de Fomento.

Seiji, Shinohara (2009), Retratos de los inmigrantes japoneses, México, DF: Foto Club Azteca Nippon Hasselblad/Artes Gráficas Panorama (edición bilingüe, español-japonés.

Serrano Álvarez, Pablo (1998), "Colima y la presencia japonesa, del Porfiriato a la Revolución”, Clío, (6)22, enero-abril, Culiacán: Universidad Autónoma de Sinaloa-Facultad de Historia, pp. 33-42.

SRE (2000), “Japón. Tratado de Amistad, Comercio y Navegación, 1888”, Tratados de México. Soberanía y territorio, 1820-1910, México, DF: Secretaría de Relaciones Exteriores, pp. 251-253.

Toda, Makoto, y Shozo Ogino (2010), "Hierba de verano, huella del sueño de los valientes. Colonización Enomoto 1897. La huella de los japoneses de la era Meiji, que vivieron intensamente en México", Separata, México, DF: Embajada de Japón en México/Cámara Japonesa de Comercio e Industria de México/Asociación México-Japonesa, pp. 65-79.

Tokugawa, Tsunenari (2009), The Edo Inheritance, (trad. Tokugawa Iehiro), Tokio: International House of Japan. 
Vázquez, Josefina Zoraida (2000a), “Los primeros tropiezos”, Historia general de México, versión 2000, 11ª reimpresión, México, DF: El Colegio de México-Centro de Estudios Históricos, pp. 574-582.

- - (2000b), "Reconocimiento y tratados comerciales: Cartas de identidad de un nuevo Estado", Tratados de México. Soberanía y territorio, 1820-1910, México, DF: Secretaría de Relaciones Exteriores, pp. 86-107.

Vlastos, Stephen (1989), "Opposition movements in early Meiji, 1868-1885", en Jansen, Marcus B. (ed.), The Cambridge History of Japan, Volume 5: The Nineteenth Century, Nueva York: Cambridge University Press, pp. 367-431. Watanabe, Chizuko (1983), The Japanese immigrant community in Mexico: Its History and present, junio, tesis de maestría, Los Ángeles, California: California State University-Department of Anthropology, pp. I-X, 1-60. Yamazaki Endo, Benito (2008), México y Japón: Crónica de 400 años de relaciones amistosas y económicas y 50 años de vínculos empresariales, México, DF: Benito Yamazaki Endo, pp. I-XXXIV, 1-93.

Yanaguida, Toshio, y Ma. Dolores Rodríguez del Alisal (1992), Japoneses en América, Madrid: Mapfre, pp. 39-41, 51-78, 141-171, 287-310.

Zavala, Silvio (1990), Apuntes de historia nacional, 1808-1974, $2^{a}$ reimpresión de la $5^{\text {a }}$ edición, México, DF: El Colegio Nacional/Fondo de Cultura Económica, pp. 87-121. 